\title{
Above and below: Military Aircraft Noise in Air and under Water at Whidbey Island, Washington
}

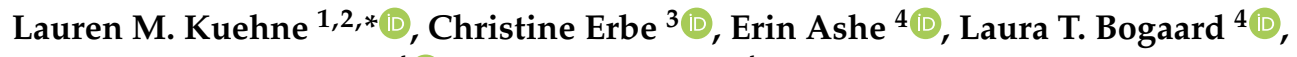 \\ Marena Salerno Collins ${ }^{4}(\mathbb{D})$ and Rob Williams ${ }^{4}$ \\ 1 School of Aquatic and Fishery Sciences, University of Washington, 1122 NE Boat Street, Seattle, \\ WA 98105, USA \\ 2 Omfishient Consulting, 2333 Seringa Avenue, Bremerton, WA 98310, USA \\ 3 Centre for Marine Science and Technology, Curtin University, GPO Box U1987, Perth, WA 6845, Australia; \\ C.Erbe@curtin.edu.au \\ 4 Oceans Initiative, 117 E Louisa St \#135, Seattle, WA 98102, USA; erin@oceansinitiative.org (E.A.); \\ laura@oceansinitiative.org (L.T.B.); marena@oceansinitiative.org (M.S.C.); rob@oceansinitiative.org (R.W.) \\ * Correspondence: lkuehne@uw.edu
}

Received: 26 September 2020; Accepted: 4 November 2020; Published: 16 November 2020

\begin{abstract}
Military operations may result in noise impacts on surrounding communities and wildlife. A recent transition to more powerful military aircraft and a national consolidation of training operations to Whidbey Island, WA, USA, provided a unique opportunity to measure and assess both in-air and underwater noise associated with military aircraft. In-air noise levels $(110 \pm 4 \mathrm{~dB}$ re $20 \mu \mathrm{Pa}$ rms and $107 \pm 5 \mathrm{dBA}$ ) exceeded known thresholds of behavioral and physiological impacts for humans, as well as terrestrial birds and mammals. Importantly, we demonstrate that the number and cumulative duration of daily overflights exceed those in a majority of studies that have evaluated impacts of noise from military aircraft worldwide. Using a hydrophone deployed near one runway, we also detected sound signatures of aircraft at a depth of $30 \mathrm{~m}$ below the sea surface, with noise levels (134 $\pm 3 \mathrm{~dB}$ re $1 \mu \mathrm{Pa} \mathrm{rms}$ ) exceeding thresholds known to trigger behavioral changes in fish, seabirds, and marine mammals, including Endangered Southern Resident killer whales. Our study highlights challenges and problems in evaluating the implications of increased noise pollution from military operations, and knowledge gaps that should be prioritized with respect to understanding impacts on people and sensitive wildlife.
\end{abstract}

Keywords: military aircraft; noise pollution; ocean noise; Endangered species; human health; animal behavior

\section{Introduction}

Military aircraft activity in the Salish Sea, Washington State, has been increasing over the past decade due to changes in operations and training for personnel out of the Naval Air Station Whidbey Island (NASWI). Although naval flights have been operating in the area for decades, the recent transition from Northrop Grumman EA-6B Prowler to the more powerful Boeing EA-18G Growler aircraft for electronic warfare has led to increases in the number of complaints about noise, including concern for area wildlife. Consolidation of nationwide training for these aircraft to NASWI increased the fleet size by $44 \%$ (from 82 to 118 aircraft) in 2019, with corresponding increases in air carrier practice, electronic warfare training, and overall base operations [1]. The changes at NASWI are reflective of a broader national trend in military base closures and consolidation, which are likely to intensify community noise and air pollution in some areas [2]. The implications of a concurrent change to more powerful aircraft and increased operations for noise pollution have not been 
measured, leaving knowledge gaps in the ability to assess vulnerability of both people and wildlife, including Endangered, Threatened or sensitive species.

Worldwide, military transportation and activities are among the least studied sources of noise pollution [3,4]. This is due to a combination of differing regulations in areas surrounding military bases and airfields [2,5], the complexity of conducting research when operation schedules are not publicly accessible, and analytical challenges in measuring and characterizing noise from periodic and intermittent activity $[3,6]$. For example, the NASWI and other airfields in the United States are not regulated by the Federal Aviation Administration as civilian airports are, resulting in more limited legal bases on which to contest aircraft noise that is disruptive. Military air traffic schedules may be classified or largely unobtainable, making it difficult to conduct monitoring or validate modeled noise data. Lastly, high-intensity but intermittent activities require alternatives to standard community noise metrics, which are geared toward more continuous sources of noise [7]. For these reasons, although studies and reviews exist on the impacts of community noise from civilian airports and highways, independent studies related to military activity are relatively rare [8] and likely to be opportunistic [3,9]. This creates crucial information gaps when the public or agencies try to evaluate the impact of proposed changes in activities [10].

While often considered an acoustic barrier, the air-water interface may effectively transmit sound in certain situations (e.g., in calm conditions and for vertical incidence; [11,12]). This opens up the need to more critically examine underwater impacts of civil and military aviation noise, which have typically been considered negligible [13]. Of paramount concern in the Salish Sea are the Southern Resident killer whales (Orcinus orca, SRKW), which were listed as Endangered under Canada's Species at Risk Act in 2001 and the U.S. Endangered Species Act (ESA) in 2005. Endangered by chemical pollution, food shortages, and vessel traffic, additional anthropogenic stressors should be examined for the potential to put recovery of SRKW out of reach. Protecting foraging areas is important because SRKWs are food-limited, and because they are more vulnerable to disturbance while feeding than during any other activity [14]. Another species of particular concern in this region is Threatened marbled murrelet (Brachyramphus marmoratus), a non-migratory seabird that makes use of protected and shallow coastal areas for foraging. In short, we see a number of compelling and timely reasons to measure in-air sound levels from Growlers to assess impacts on humans and terrestrial wildlife, and explore whether Growler noise is audible under water in areas used by SRKWs, marbled murrelet, and other wildlife.

In this study, we evaluated the potential bioacoustic impacts of noise from Growlers and implications for the Puget Sound and Salish Sea region. Noise pollution is usually studied as a public health issue for people [3], or, less commonly, as an anthropogenic impact on wildlife [8]. Terrestrial and aquatic impacts and species are usually considered and studied separately. Though understandable, this compartmentalizing does not acknowledge the cascading changes that can occur in ecosystems as a result of new noise sources, or that anthropogenic noise impacts species and taxonomic groups broadly $[15,16]$. In this study, we therefore adopted an integrative approach by measuring both in-air and underwater noise, and then interpreting those levels against established impacts for humans as well as sensitive terrestrial and aquatic wildlife. Our study seeks to answer two questions: (1) Does noise from military aircraft have the potential to impact aquatic as well as terrestrial habitats? and (2) How do measured levels in air and under water compare with thresholds known from previous studies to impact humans, terrestrial, and marine wildlife? We then use these results to critically examine the processes by which noise impacts are assessed and mitigated, helping to bridge the gap between monitoring and management of noise pollution. 


\section{Methods}

\subsection{Study Area}

Whidbey Island, where NASWI is located, is near the border of Canada and the United States of America, and forms the northern border of Puget Sound. The island is approximately $88 \mathrm{~km}$ long, and $2.4-19 \mathrm{~km}$ wide; it is the largest island in Washington State. Whidbey Island was historically inhabited by people of multiple Native American tribes that maintain reservations in the surrounding area today, including the Lower Skagit, Swinomish, Suquamish, and Snohomish. The island is currently home to 70,000 residents living in multiple medium- and small-sized communities. The majority of the island's economic activity is directly or indirectly related to the Navy's presence, but other economically important activities include farming, fishing, tourism, and real estate/vacation home purchases. Public concerns about impacts from NASWI are not limited to Whidbey Island, but are present throughout Island County, which relies on a reputation for remote and peaceful tourist opportunities (e.g., the San Juan Islands).

The NASWI is the largest single employer on Whidbey Island, with a base population of approximately 10,000 soldiers, civilians, and contractors. NASWI was first commissioned and constructed in the early 1940s and has undergone various eras of expansion and contraction. Currently, NASWI consists of two airfields (Ault Field and OLF Coupeville) with four runways (Figure 1a). Aircraft are housed at Ault Field, but both airfields are used for field carrier landing practice (FCLP) by Growlers. FCLPs are intended to replicate conditions for carrier-based takeoffs and landings and feature repeated "touch-and-go" flights; a certain number of these must be conducted at night to adequately prepare pilots. Although FCLP is the dominant type of aircraft training at NASWI, other base aircraft activities include electronic warfare and air-to-air combat training in nearby military operations areas [10], submarine detection, and cargo aircraft training [17].

Schedules for base activities are not published, with the exception of a courtesy (i.e., non-official) notification of the airfield and approximate time frame for FCLPs for that week [18]. Information on base operations, aircraft activity, and corresponding noise impacts is otherwise available only in the form of general estimates (e.g., annual operations, modeled maximum loudness in selected areas) conducted as part of the Environmental Impact Statement (EIS) process [17] and corresponding Biological Opinions for ESA-listed species [19]. The U.S. Department of Defense policy is to model rather than monitor noise from military operations, and no noise monitoring has been done by the U.S. Navy to date.

\subsection{In-Air Acoustic Data Collection}

Growlers were recorded in air at Moran County Beach Park $(48.3693,-122.6662)$, the nearest public location from the underwater recording site (see below) on September 13 and 16, 2019, and located under FCLP flight track 14 for Ault Field (Figure 1b). On both days, FCLPs were scheduled from "Morning to Late Afternoon", and were done on track 14, with jets circling south to north; as a result, the recorder was capturing sound associated with landings. An observer logged the type and number of all visible and (in the case of takeoffs) audible aircraft events and noted the direction of travel and flight activity as landing, pass, or takeoff. A Songmeter SM4 autonomous recorder (Wildlife Acoustics, Maynard, MA, USA) collected audio data from aircraft landings and flyover events. Sound was sampled at $48 \mathrm{kHz}$ and with zero gain added. The Songmeter was deployed between 0930 and $1530 \mathrm{on}$ September 13 and between 1100 and 1500 on September 16. A sound level data logger (Extech 407760; Nashua, NH, USA) was deployed at the same time recording A-weighted sound levels (dBA) at 1-s intervals; however, the data logger failed to record on the 13th, so simultaneous sound pressure levels were collected with audio data on September 16 only. 

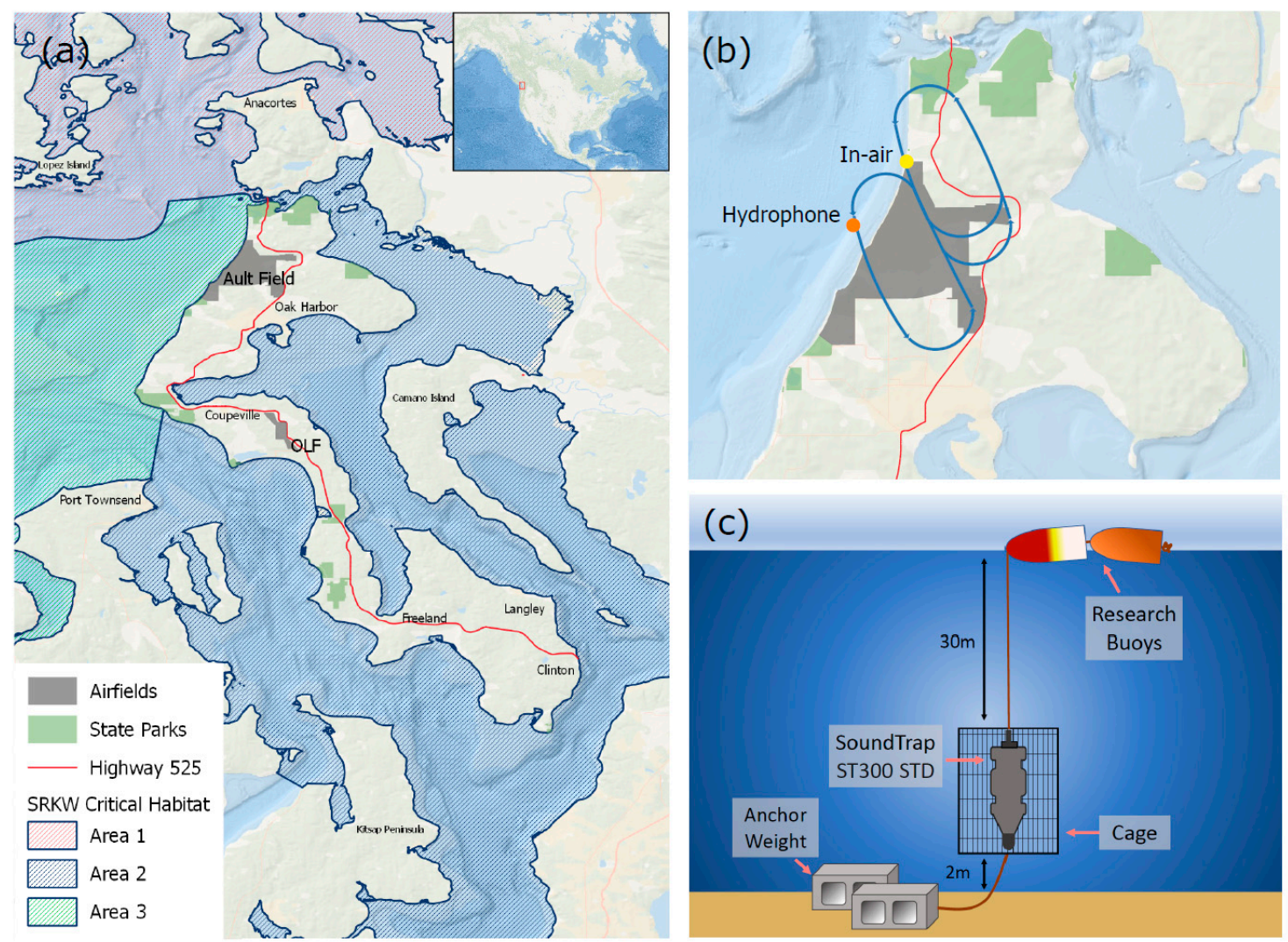

Figure 1. Map of the study area, location of underwater and in-air sound recordings, and schematic of hydrophone mooring. (a) Whidbey Island and surrounding areas, showing the location of Naval Air Station Whidbey Island's two airfields (Ault Field and OLF), largest cities and towns, and state parks. Critical habitat areas (Areas 1-3) for Endangered Southern Resident killer whales are shown. (b) Location of SoundTrap (orange circle) and in-air recordings (yellow circle) relative to Ault Field and field carrier landing practice (FCLP) flight tracks 32 and 14 (blue lines). Flight tracks were georeferenced from the Environmental Impact Statement [17]; two other flight tracks around Ault Field (tracks 7 and 25, oriented east-west) are not shown. (c) Schematic of the SoundTrap mooring, which was deployed from 15 August-11 September 2019. The SoundTrap was housed in a coated wire cage attached to a concrete block anchor with a $2 \mathrm{~m}$ line; a $30 \mathrm{~m}$ line attached to buoys kept the SoundTrap suspended above the sea floor.

The number of aircraft events during the FCLPs on September 13 and 16 was summarized from the visual observations for the period of 1100-1500 (when FCLP activity occurred) on both days. To provide a visual representation of the timing and duration of FCLPs, long-term spectral averages (LTSAs) were generated for the same periods each day in MATLAB, using 1-s and 1- $\mathrm{Hz}$ resolutions.

\subsection{Underwater Acoustic Data Collection}

Growlers were recorded under water with a SoundTrap 300 STD autonomous recorder (Ocean Instruments, Auckland, New Zealand) that was factory-calibrated and programmed to record continuously at $96 \mathrm{kHz}$ sampling frequency (fs) prior to deployment. The SoundTrap was deployed off the northwest coast of Whidbey Island, approximately $1400 \mathrm{~m}$ from the end of the east-west runway and $1000 \mathrm{~m}$ from the shoreline (Figure $1 \mathrm{~b}$ ). This location is below the path of aircraft taking off to the west, and FCLP flight tracks 7 and 32.

The SoundTrap was suspended in a metal cage $2 \mathrm{~m}$ above the sandy mud sea floor, and was moored using a system of concrete blocks, sinking line, and two floats (Figure 1c). The SoundTrap was deployed twice for two weeks, totaling 28 days of data collection. In between deployments, the SoundTrap was retrieved for charging and downloading data. It was first deployed on 15 August 
2019, at 13:54 PDT at 48.3492,-122.6917, at a depth of $33.2 \mathrm{~m}$, and then on August 29, 2019, at 12:12 PDT, in a similar location $(48.3494,-122.6907)$, at a depth of $34.7 \mathrm{~m}$. The weather throughout this month was variable, consisting of rain, wind, sun, and clouds. Growlers taking off to the west flew over the SoundTrap at an altitude of 120-190 m above sea level.

\subsection{Data Analysis}

Visual observations confirmed the occurrence of 23 single Growler flights over the Songmeter on September 16, during an FCLP session with only one aircraft operating. Opportunistic observations on four dates (August 15, 28, 29, and September 12) visually confirmed the occurrence of ten Growler flights over the SoundTrap. These overflights were manually identified in the recordings using Audacity@ (Version 2.3.2; retrieved 20 September 2019 from https://audacityteam.org/) and a 15-s audio file was saved for each overflight. The audio files were analyzed using a custom script in MATLAB (version 2018b; The MathWorks Inc., Natick, MA, USA). Each 15-s file was calibrated and then Fourier-transformed in 1-s Hann windows (i.e., the number of Fast Fourier Transform components NFFT equaled the number of samples per second) with $67 \%$ overlap. A time series of band levels was computed between $20 \mathrm{~Hz}$ and $20 \mathrm{kHz}$, corresponding to the frequency band occupied by Growler overflights. The peak band level was assumed to correspond to the time when the plane was directly overhead. The mean-square sound pressure spectral density (in short, power spectral density, PSD; [20]) from the corresponding 1-s window was saved. A 140-min sample of underwater ambient noise (i.e., sound received at this location from all sources but the signal of interest: airplane noise) was collated from before, in between, and after the overflights, and also calibrated and Fourier-transformed in 1-s Hann windows with $67 \%$ overlap.

Over all overflights, median and quartile PSD levels, one-third octave band levels, and weighted levels were computed. One-third octave band levels were obtained by integrating the PSD into bands that are $1 / 3$ of an octave wide, then applying $10 \times \log _{10}$ [20]. One-third octave band levels were compared to published audiograms to estimate which parts of the in-air and underwater noise spectra might be audible to the two ESA-listed species (SRKW and marbled murrelet), and at what levels. Audiogram data were extracted from publications using the software program WebPlotDigitizer (Version 4.2; A. Rohatgi, Pacifica, CA, USA) if data tables were not published. The killer whale underwater audiogram followed the model proposed by Branstetter et al. (2017) [21]. In the absence of killer whale critical ratio data across the frequency band of Growler noise, one-third octave bands were used as a conservative estimate (see Figure 4A in Erbe et al. 2016) [22]. There is no audiogram available for marbled murrelet, so audiograms of other seabirds were used as surrogates. In-air and underwater audiograms for cormorant (Phalacrocorax carbo sinensis) were measured by Johansen et al. (2016) [23], the in-air audiogram for the lesser scaup (Aythya affinis) duck by Crowell et al. (2016) [24], and the in-air audiograms for common murre (Uria aalge) and Atlantic puffin (Fratercula arctica) by Mooney et al. (2019) [25]. One-third octave bands were also used for the birds in air and under water $[24,26]$. We report A-weighted levels for humans as well as audiogram-weighted levels for the animals in air and under water. Audiogram-weighting involved filtering the sound spectrum by the animal audiogram prior to integration over frequency. In praxis, the audiogram was interpolated to $1-\mathrm{Hz}$ resolution for comparison to the noise spectrum, also in $1-\mathrm{Hz}$ resolution. Over the range of frequencies where the noise PSD levels exceeded the audiogram levels, the audiogram levels were subtracted from the noise PSD levels at each frequency, yielding differences in $\mathrm{dB}$ at each frequency. Differences were converted to linear quantities (by applying $10^{\wedge}($ level $/ 10)$ ), which were then integrated over frequency, and the result was converted to a level-quantity (by taking $10 \times \log _{10}$ ), yielding the audiogram-weighted level in dBth.

To evaluate the scope of potential impact at the ecosystem level, we compared the distribution of recorded (i.e., received) levels in air and under water with thresholds of behavioral and physiological stress responses for humans and a suite of representative terrestrial and marine species. Selection of representative species, responses, and thresholds from the literature was guided by two criteria: if the 
species occurred in or was a reasonable surrogate for species in the Salish Sea area, and if the study used noise stimuli that was a sensible proxy (i.e., low-mid frequency, broadband) for aircraft noise. Whenever possible, studies that established or modeled a noise-dose relationship were used; in the case of modeled probability, the $50 \%$ likelihood of response was used as the threshold. Despite recognition that human-weighting of sound pressure levels is understood to be potentially unsuitable for wildlife [16,27], we found that most terrestrial studies nonetheless evaluated responses to A-weighted sound pressure levels. In addition to thresholds for people [28,29], the final suite of terrestrial species (or genus) contrasted against in-air received levels were: marbled murrelet [30], owls [31-33], harlequin duck (Histrionicus histriónicas) [34], and caribou (Rangifer tarandus) [35]. Marine species selected for contrast with underwater received levels were: killer whales [36], common murre [37], harbor porpoise (Phocoena phocoena) [38], herring (Clupea harengus) [39], and California sea lion (Zalophus californianus) [40].

Although our study design did not allow for comparison of underwater sound from Growlers with other surface-confirmed anthropogenic sources (in this area, primarily boats), we used LTSAs to visually represent and contrast underwater sound from Growlers and vessels. We used the weekly notifications of FCLPs (Table S2) to focus on dates and time periods (e.g., "Midmorning", "Late Afternoon") when training was scheduled for Ault Field, and created LTSAs for these periods (1-s and 1-Hz resolutions) to identify periods when both Growler noise and vessel noise were present. Three 1-h LTSAs were generated to visualize the underwater soundscape under varying flight and vessel activity.

\subsection{Comparison of Sound Levels and Flight Activity with Prior Studies}

To place sound levels and flight activity at NASWI in the context of those documented in other studies, we conducted a literature review to identify studies of impacts of military low-altitude flights (MLAF) on people and wildlife. We restricted our search to these studies because the noise strength, onset rate, and intermittent nature of MLAF are distinct from commercial or general aviation aircraft $[7,41]$. In particular, comparable environmental noise levels ( $>100 \mathrm{dBA})$ are encountered only rarely in other contexts [3]. Our initial search resulted in 26 primary research articles that evaluated impacts of MLAF on people or communities (i.e., annoyance, hearing damage or loss, and effects on mental and physical health), and 34 articles that examined impacts on wildlife (Data S1). A subset was removed before extracting noise data; reasons for exclusion included inability to obtain full articles, reporting of events only (vs. noise), or non-relevant context (e.g., air shows) (Data S1); some studies also had multiple publications related to the same dataset (Table S1). The final number of studies from which noise metrics were extracted was 12 (people) and 18 (wildlife) (Table S1). The number of studies that have measured or modeled impacts of underwater noise from aircraft was too low for meaningful analysis, and included studies therefore only reflect in-air conditions.

From each study, three metrics were extracted or estimated: (1) maximum received sound level, (2) typical or average number of daily events $>100 \mathrm{dBA}$, and (3) total daily duration in seconds $>100 \mathrm{dBA}$ (Table S1). If a typical number of daily MLAF events was not reported, we calculated the average number of daily events as the total reported events divided by the number of days when recording took place; since military activity usually occurs almost exclusively on weekdays, weekend days were excluded from this formulation. A threshold of $100 \mathrm{dBA}$ was used because it was relevant to the current study and is frequently used as a reporting threshold, facilitating the extraction of metrics across disparate studies that could include events both below and above that threshold.

The region of study, year in which the study was conducted, and (for wildlife) the focal taxonomic group were also extracted. If a study included multiple noise treatments or examined geographic areas with different received levels, metrics were extracted for each treatment or geographic area. If the duration of individual flight events was not reported, a conservative estimate of 4 s per overflight event (based on mean reported event duration across all field studies) was used (Table S1). The same metrics were then calculated for the current study using the sound pressure level data and observed flight events from September 13 and 16. These two dates do not represent maximum daily periods 
with FCLPs, which is up to 8 time periods per day, but typical and moderate activity on training days (Table S2). The relative positions of different studies with respect to the three metrics were contrasted separately for people and wildlife.

\section{Results}

\subsection{Sound Levels, Audibility, and Response Thresholds}

The waveform and spectrum of an example overflight recorded in air are shown in Figure 2a. Broadband levels $(20 \mathrm{~Hz}-20 \mathrm{kHz})$ exceeded $117 \mathrm{~dB}$ re $20 \mu \mathrm{Pa}$ for about $1 \mathrm{~s}$ in this example.

Averaged over all 23 overflights, the received level was $110 \pm 4 \mathrm{~dB}$ re $20 \mu \mathrm{Pa}$ rms and $107 \pm 5 \mathrm{dBA}$; maximum received levels were $119 \mathrm{~dB}$ re $20 \mu \mathrm{Pa}$ and $118 \mathrm{dBA}$. In-air noise covered a frequency band from $20 \mathrm{~Hz}$ to greater than $10 \mathrm{kHz}$, peaking between $50 \mathrm{~Hz}$ and $1 \mathrm{kHz}$ (Figure 3a). Comparing ${ }^{1} / 3$ octave band levels with audiograms indicated that in-air noise from Growlers would be audible to all species within the limits of the audiogram measurements available, which ranged from a minimum of $250 \mathrm{~Hz}$ for cormorants to a maximum of $8 \mathrm{kHz}$ for ducks (Figure 3b). Audiogram-weighted levels suggested that murre might experience less disturbance (18-28 dBth) from Growlers compared with puffins (60-65 dBth), cormorants (65-71 dBth), and ducks (81-88 dBth; Table 1). A-weighted noise levels experienced by people ranged from 104 to $109 \mathrm{dBA}$.

The waveform and spectrum of an example overflight recorded under water are shown in Figure $2 \mathrm{~b}$. Broadband levels exceeded $131 \mathrm{~dB}$ re $1 \mu \mathrm{Pa}$ for about $1 \mathrm{~s}$ in this example. Averaged over the 10 overflights, the received level in the strongest 1 -s window was $134 \pm 3 \mathrm{~dB}$ re $1 \mu \mathrm{Pa}$ rms. The underwater noise recorded during the 10 overflights covered a frequency band from $20 \mathrm{~Hz}$ to $30 \mathrm{kHz}$, peaking between $200 \mathrm{~Hz}$ and $1 \mathrm{kHz}$ (Figure 4a). Based on intersection with audiograms, Growler noise penetrating the water was expected to be audible to killer whales between $200 \mathrm{~Hz}$ and $40 \mathrm{kHz}$, and to cormorants between $1 \mathrm{kHz}$ and $4 \mathrm{kHz}$ (Figure $4 \mathrm{~b}$ ). Audiogram-weighted levels indicated Growler flights would result in $48-56 \mathrm{dBth}$ of noise for killer whales, and $40-44 \mathrm{dBth}$ for cormorants (Table 1).

(a)
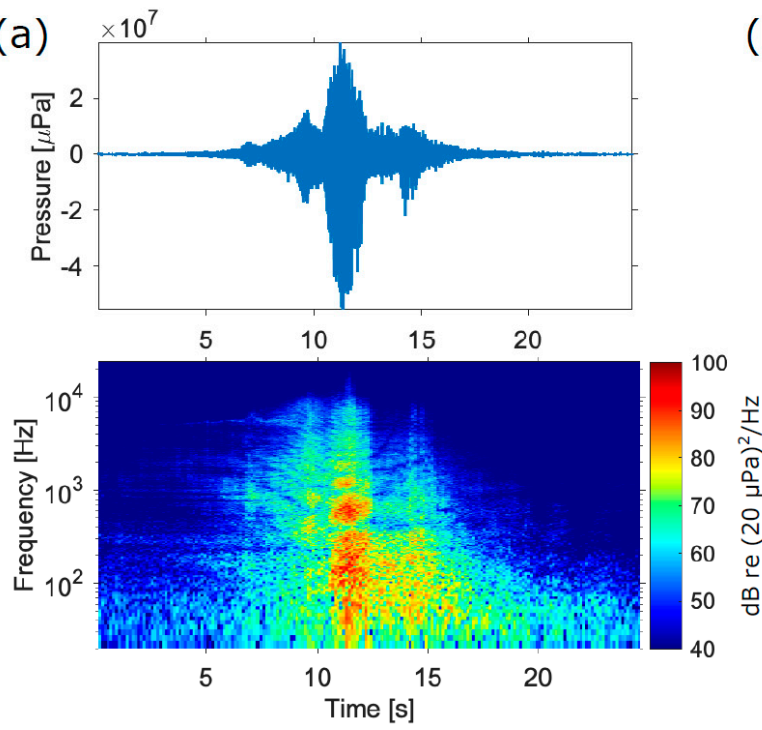

(b)
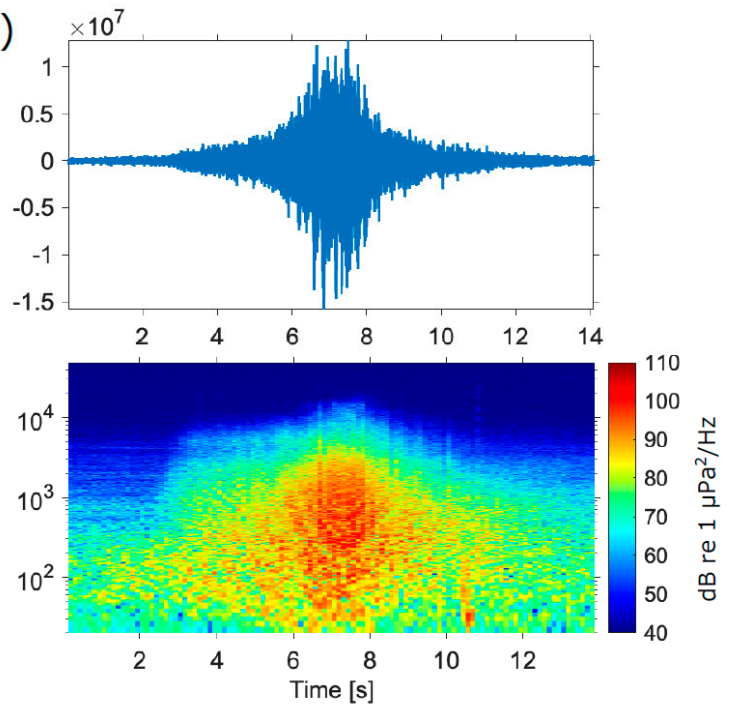

Figure 2. Waveform (top) and spectrogram (bottom) of (a) a Growler overflight recorded in air (fs $=48 \mathrm{kHz}, \mathrm{NFFT}=12,000,50 \%$ overlap) and (b) a Growler overflight recorded under water (fs $=96 \mathrm{kHz}, \mathrm{NFFT}=24,000,50 \%$ overlap). 

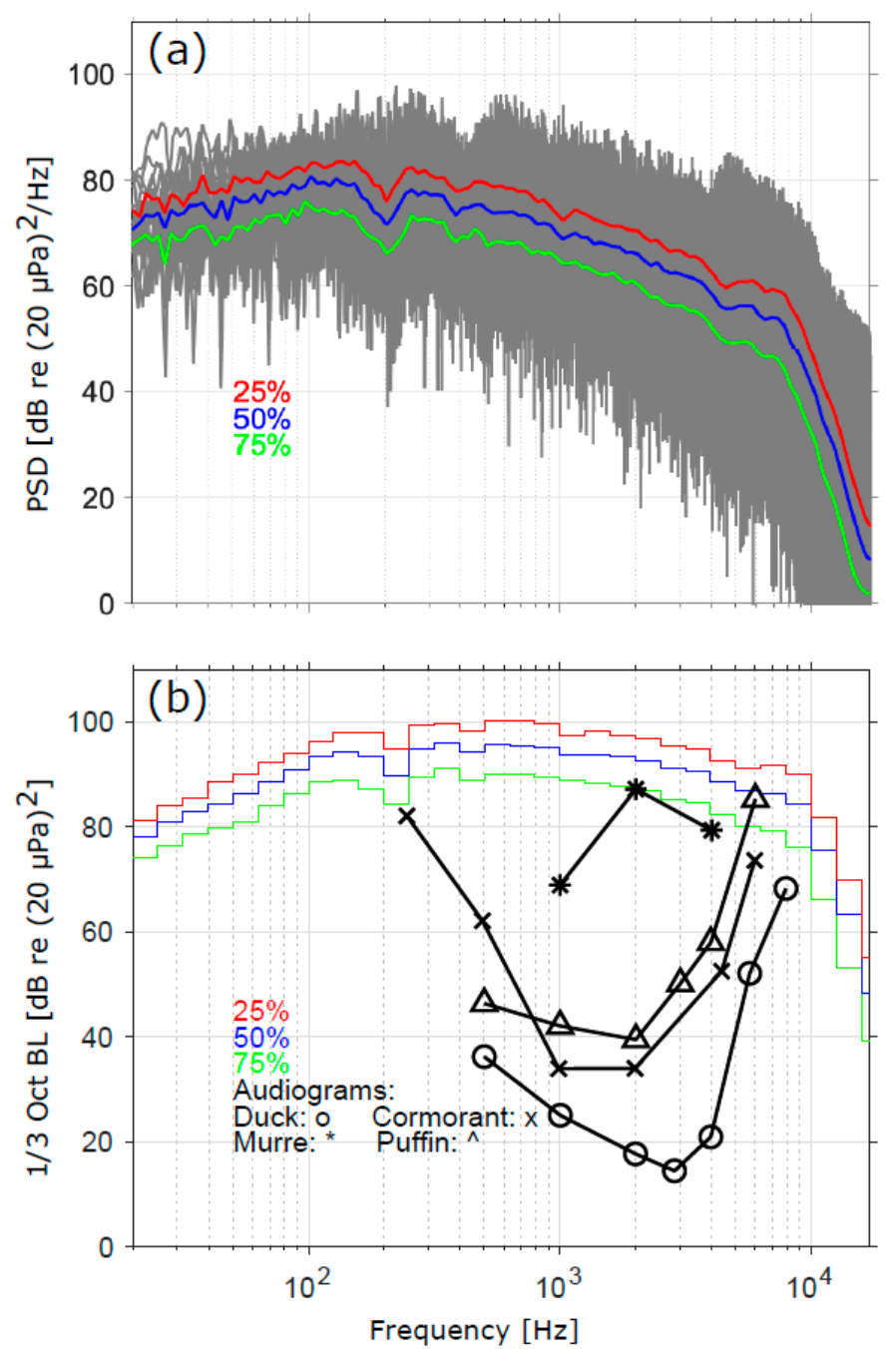

Figure 3. In-air (a) received power spectral density (PSD) from 23 overflights (grey), and median (blue) and quartile (red and green) levels. (b) One-third octave band levels (median and quartiles; blue, red, and green, respectively) are compared to the in-air audiograms of cormorants, ducks (i.e., lesser scaup), murres, and puffins. Noise above the audiogram lines is expected to be audible.

Table 1. Median and quartile audiogram-weighted levels (dBth) for killer whales and seabirds, and A-weighted levels for humans.

\begin{tabular}{cccccccc}
\hline & \multicolumn{2}{c}{ Under Water } & \multicolumn{5}{c}{ In Air } \\
\cline { 2 - 8 } & $\begin{array}{c}\text { Orca whale } \\
(\mathbf{d B t h})\end{array}$ & $\begin{array}{c}\text { Cormorant } \\
\mathbf{( d B t h )}\end{array}$ & $\begin{array}{c}\text { Duck } \\
\mathbf{( d B t h )}\end{array}$ & $\begin{array}{c}\text { Cormorant } \\
\text { (dBth) }\end{array}$ & $\begin{array}{c}\text { Murre } \\
\text { (dBth) }\end{array}$ & $\begin{array}{c}\text { Puffin } \\
\text { (dBth) }\end{array}$ & $\begin{array}{c}\text { Human } \\
\text { (dBA) }\end{array}$ \\
\hline $25 \%$ & 56 & 44 & 88 & 71 & 28 & 65 & 109 \\
\hline $50 \%$ & 54 & 42 & 84 & 69 & 25 & 63 & 107 \\
\hline $75 \%$ & 48 & 40 & 81 & 65 & 18 & 60 & 104 \\
\hline
\end{tabular}


When compared with thresholds of behavioral and physiological stress responses in humans and a suite of terrestrial wildlife (i.e., terrestrial birds and mammals), we found that in-air received levels exceeded all identified thresholds (Figure 5a). Underwater received levels exceeded thresholds of startle response for common murre and avoidance by killer whales. The strongest received levels exceeded the threshold of startle response for herring and harbor porpoise, but were below those associated with avoidance in California sea lions (Figure $5 b$ ).
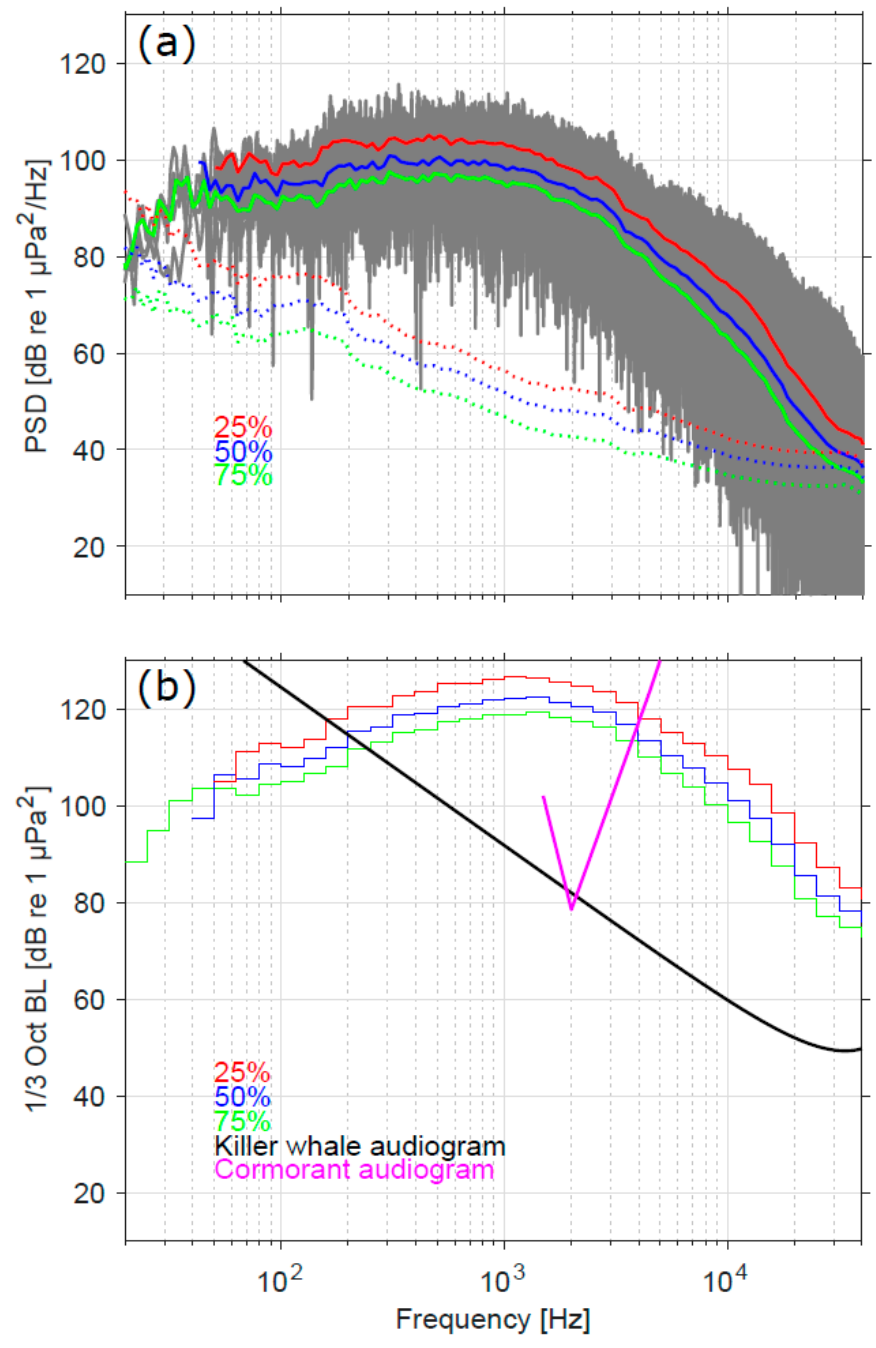

Figure 4. Underwater (a) received power spectral density (PSD) from 10 Growler overflights (grey), with median (blue) and quartile (red and green) levels. Ambient noise percentiles at the time of recording are shown in dotted curves. (b) One-third octave band levels (median and quartiles; blue, red, and green, respectively) shown together with the killer whale (black) and cormorant (pink) underwater audiograms. Noise above the audiogram lines is expected to be audible.

LTSAs of in-air recordings show the pattern of FCLPs as 30-60 min periods of rapid consecutive flights interspersed with shorter intervals of reduced or no flights (Figure S1). Underwater noise was detected on multiple dates and time periods when FCLPs were scheduled, with the same pattern of clustered activity (Figure 6a,b). Visual contrasts of underwater noise from FCLPs and routine takeoffs show the unique characteristics of sound from Growlers compared to vessels, and that received levels from Growlers are likely to exceed those associated with a range of typical vessel noise (Figure $6 \mathrm{a}-\mathrm{c}$ ). 


\subsection{Comparison of Sound Levels and Flight Activity with Prior Studies}

On September 13, 185 landings and overhead passes of aircraft at the north end of Ault Field occurred between 1100 and 1500. Of these, all but two (1 Boeing 737 and 1 DC-9) were EA-18G Growlers engaged in FCLPs. The majority of overhead passes were a single aircraft, but passes with up to three aircraft simultaneously were observed. Seventeen events of Growlers taking off to the south were audible but not visible. On September 16, 83 passes or landings were observed during the same time period; of these, three were Boeing 737 and 10 were P-3s. The remaining 70 events were Growlers, with a maximum of two aircraft observed at any one time; 13 events of Growlers taking off were also audible but not visible.
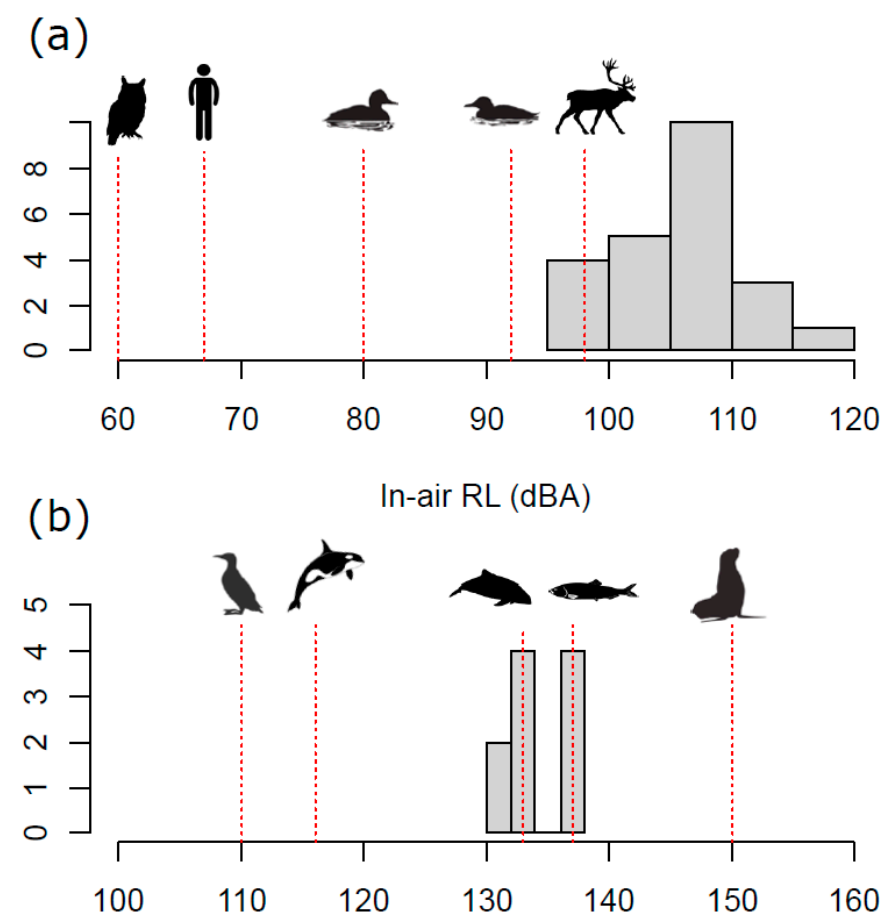

Underwater RL (dB re $1 \mu \mathrm{Pa})$

Figure 5. The distribution of received levels (RL) for (a) 23 in-air overflight events and (b) 10 flight events recorded under water relative to thresholds known to cause behavioral and physiological responses in humans and representative suites of terrestrial and marine wildlife. In-air: owls, $60 \mathrm{dBA}=$ physiological stress responses [31], 50\% chance of nest flushing [32], and 50\% reduction in the probability of prey detection and hunting strikes [33]; humans, $67 \mathrm{dBA}=50 \%$ probability of awakening at night [29] and increases in nighttime blood pressure [28]; harlequin duck, $80 \mathrm{dBA}=$ reduced courtship and increased vigilance and agonism [34]; marbled murrelet, $92 \mathrm{dBA}=$ risk of disturbance in nesting marbled murrelets [30]; caribou, 98 ASEL (A-weighted sound exposure level) = interrupted resting bouts and increased activity [35]. (Note: The threshold for caribou was reported in ASEL which likely overestimates RL (dBA).) Underwater: common murre, $110 \mathrm{~dB}$ re $1 \mu \mathrm{Pa}=$ startle response and interrupted feeding [37]; killer whales, $116 \mathrm{~dB}$ re $1 \mu \mathrm{Pa}=$ evading noise from small boats [36]; harbor porpoise, $133 \mathrm{~dB}$ re $1 \mu \mathrm{Pa}=50 \%$ probability of startle response to low- and mid-frequency up/downsweeps [38]; herring, $137 \mathrm{~dB}$ re $1 \mu \mathrm{Pa}$ = startle response to recorded boat noise [39]; California sea lions, $150 \mathrm{~dB}$ re $1 \mu \mathrm{Pa}=50 \%$ probability of avoidance of area with a simulated mid-frequency tactical sonar signal [40]. 
When the three metrics of maximum received level, daily number of events, and daily duration $>100$ dBA were contrasted with those in previous studies that assessed impacts of MLAF, the combined sound levels and flight activity associated with FCLPs exceeded those in most other studies (Figure 7). In studies related to people, some documented louder maximum received levels, but with fewer events and cumulative daily durations (Figure 7a). Similarly, cumulative daily duration was substantially exceeded in only one previous study; however, the received levels were lower (110 vs. $118 \mathrm{dBA}$ ). Overall, the sound levels and flight activity we describe in this study bear the strongest similarity to the most extreme areas around airfields on Okinawa, which were measured opportunistically between 1968 and 1972, and then systematically in 1998 (Table S1a). Contrasts with studies for wildlife show that when all three metrics are considered, sound levels and flight activity at NASWI are largely incomparable to most prior studies (Figure 7b). The taxonomic groups that have been evaluated for impacts of MLAF include ungulates (caribou, sheep, deer, and horse), one species of raptor, four species of ducks, two rodents, and one reptile (Table S1b).

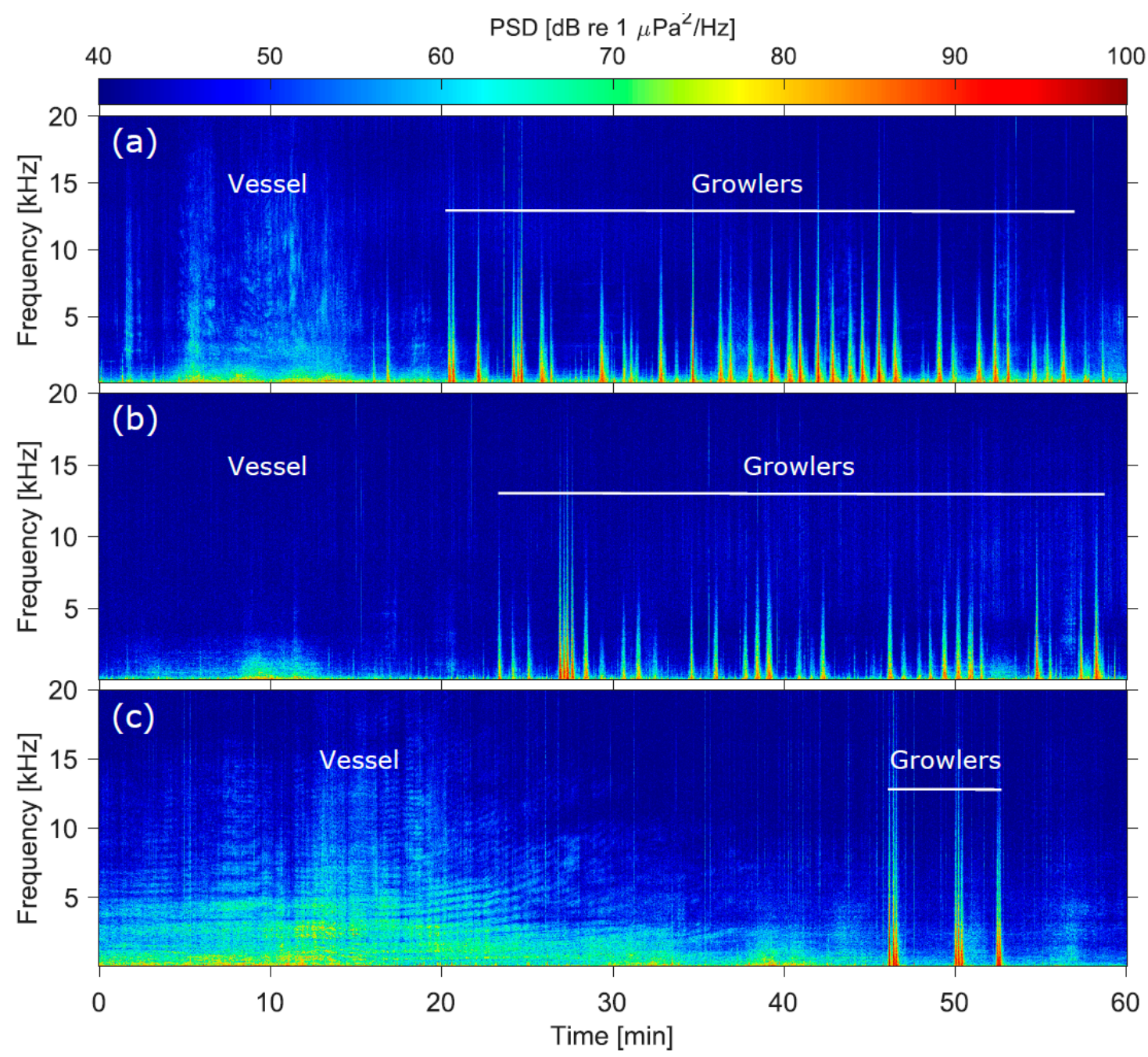

Figure 6. One-hour spectrograms ( $\mathrm{fs}=96 \mathrm{kHz}, \mathrm{NFFT}=96,000,0 \%$ overlap) contrasting underwater sound from Growlers juxtaposed with examples of vessel noise: (a) FCLP sessions on 20 August (0940-1040), (b) FCLP sessions on August 27 (1930-2030) and (c) typical clusters of consecutive takeoffs (2-3 Growlers per cluster) on September 4 (0915-1015). 


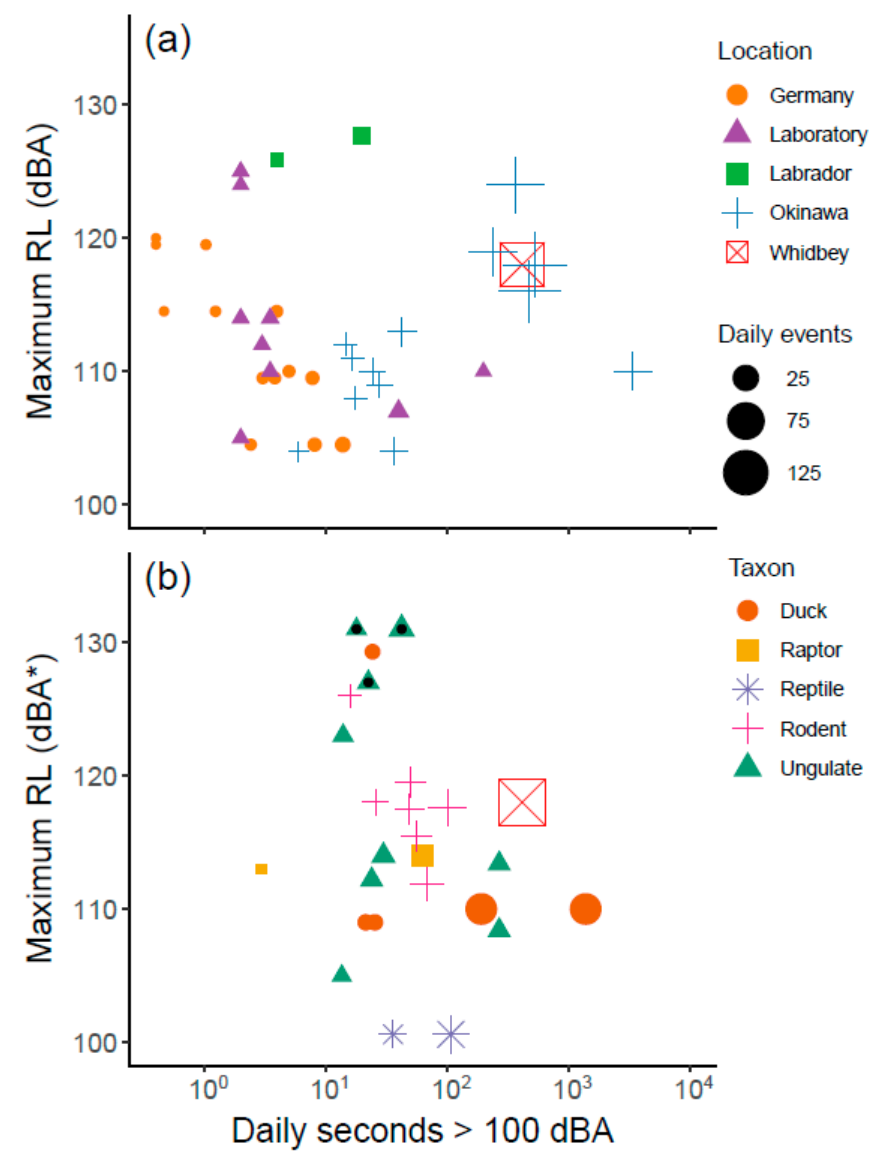

Figure 7. Maximum received level (RL), cumulative daily duration in seconds $>100 \mathrm{dBA}$, and the daily number of events in the current study (Whidbey) and previous studies of impacts of military low-altitude flights (Table S1) related to (a) people and communities and (b) wildlife. Colored symbols reflect (a) geographic region and (b) broad taxonomic group, with the daily number of events represented by the size of the symbol. Maximum received levels in studies were typically reported as A-weighted sound pressure levels ( $\mathrm{dBA})$ or $\mathrm{dBA}$ could be calculated, $\left({ }^{*}\right)$ with the exception of 3 data points from wildlife studies (black dot inside symbol) that exclusively reported either C-weighted sound pressure levels or A-weighted sound exposure level (Table S1); the exceptions were included as these metrics are expected to overestimate RL (dBA).

\section{Discussion}

In this study, we measured noise from an infrequently studied source of MLAF, operating in close proximity to residential sites, recreational areas, and habitat for multiple sensitive marine species. Our goal was to evaluate potential impacts on people and wildlife, using thresholds of response that have been established in previous studies. We measured sound both in air and under water and compared received levels with species-specific audiograms to demonstrate the extent to which noise from Growlers is perceived by sensitive wildlife. We also place the measured noise (i.e., received levels, total daily duration, and number of events) in the context of studies that have assessed impacts of MLAF on people and wildlife. By adopting this integrated approach, our study is uniquely positioned to illustrate knowledge gaps that can undermine assessment of noise impacts.

When we considered noise as a totality of received level, frequency of events, and total daily duration, the sound levels and flight events exceeded those in most previous studies. This finding is critical because it indicates that assessments of impact (e.g., the EIS) are, by definition, based largely on studies that have evaluated responses of people and wildlife to fewer and quieter MLAF events. To find where similar sound levels are experienced by people, we would have to turn to industrial and occupational noise studies, including those for military personnel (e.g., [42]). However, extrapolating 
from these studies to a community noise context is largely inappropriate given differences in the type and duration of exposure as well as occupational regulations such as time exposure limits, use of hearing protection, and testing [43].

In our review of MLAF studies for people, we found that comparable community or environmental noise has been studied in only one other region of the world, on Okinawa Island, Japan. From World War II until 1998, Okinawa Island had 39 U.S. military facilities (today there are 28), including two major bases of Kadena Air Base and Futenma Air Station. Noise from aircraft was measured opportunistically around these bases in 1968 and 1972 (during the Vietnam War), but were not measured systematically until 1998, when a multi-year study evaluated consequences for health and well-being. The study was launched because at the time it was estimated that $38 \%$ of Okinawa's population were living in conditions that exceeded the national standards for exposure to aircraft noise [6]. It is notable that the sound levels and flight activity we document around Whidbey Island are similar to Okinawan measurements during the Vietnam War, prior to passage and adoption of national noise regulations by Japan's Environment Agency in 1973 and the Defense Facilities Administration Agency in 1980.

The same trend was apparent when we compared the maximum received level, number of events, and total daily duration with studies related to wildlife. Only one wildlife study, conducted in a laboratory, exceeded the total daily duration that we measured. Although some studies evaluated exposure to stronger maximum received levels, cumulative daily duration was less. For example, one of the most comprehensive assessments conducted by Goudie and Jones (2004) examined behavioral responses of harlequin ducks to MLAF, finding reduced courtship and increased agonism at a threshold of $80 \mathrm{dBA}$, with recovery requiring about two hours [34,44]. Although Goudie and Jones (2004) recorded a higher maximum sound pressure level, the typical number of daily events was just $3 \%$ of the number we document in the current study. This example illustrates the difficulty in assessing impacts of increased Growler training on area wildlife. We face not only general research limitations in how noise impacts communication, behavior, foraging, and ultimately fitness of wildlife $[8,16]$ but an added burden of extrapolating to a number of events, received levels, and cumulative daily duration that is largely unstudied.

We considered carefully whether sampling decisions or assumptions made during analysis could have inflated the number of events, received levels, or cumulative daily duration. Recordings of in-air noise were done over two days, which could be considered non-representative (e.g., if an extreme number of events were recorded). However, when we compiled the FCLP schedule for the past 4 years, we found that our sampling days, with two published active time frames, represented typical and moderate training activity for a single day. The number of flight events and received levels we recorded were also consistent with previous monitoring of Growlers on Whidbey Island. Between 2013 and 2019, noise and events from FCLPs have been measured periodically at 12 locations around Coupeville OLF. The daily number of flight events associated with FCLPs ranged from 69 to 239, easily encompassing our calculated average of 127 events per training day [45-48]. Similarly, maximum sound levels in previous sampling ranged from 97 to $121 \mathrm{dBA}$ (depending on distance from the flight track in use), a range that also encompasses our maximum of $118 \mathrm{dBA}$.

Knowledge of the consequences for health and well-being of people experiencing these numbers of flight events and cumulative daily duration of noise exposure is necessarily limited, given that similar conditions have been rarely studied. The investigations by the Okinawa Prefecture in the mid-1990s offer the best available information on implications for public health. One of these associated studies found that noise from aircraft around the Kadena airbase was hazardous and sufficient to cause hearing loss among the population as a whole [49], while an epidemiological study identified individuals with noise-induced hearing loss that was likely due to living in proximity to the base $[6,50]$. In a different region of the world, Finnish Air Force investigations found that two claims of hearing loss from MLAF events were plausible based on measured exposures [51]. A unique laboratory study examining temporary threshold shift and stapedius reflex period concluded that $114 \mathrm{dBA}$ (below our 
measured maximum) was a critical threshold, where repeated exposure to military aircraft noise above this was likely to result in noise-induced hearing loss [52].

Studies have also documented consequences for cardiovascular health within the noise exposures that we measured. Clear dose-response relationships existed between blood pressure and aircraft noise surrounding Kadena and Futenma airbases, with noise-exposed groups exhibiting a 30\% increase over control groups [6]; risk of hypertension due to noise exposure was highest for older age groups [53]. Laboratory studies have demonstrated short-term increases in blood pressure following exposures to military aircraft noise, with suggested response thresholds ranging from 90 [54] to $106 \mathrm{dBA}$ [55]. Other aspects of human health and well-being including annoyance, sleep disturbance, resident dissatisfaction, and even low birth weights have been studied and associated with high-intensity exposure specifically from military aircraft $[6,41,56-58]$ as well as at lower levels of community noise from civilian aircraft and other sources [4,59]. As a result of reviewing these and other studies, in 2017 the Washington State Department of Health recommended that the U.S. Navy conduct a health impact assessment as part of the EIS process [60]. Our results confirm the need for such an assessment to occur.

The strength of the noise from flight events resulted in another critical finding from this study, where we document sound from Growlers $30 \mathrm{~m}$ below the sea surface, and at levels known to trigger behavioral changes for aquatic wildlife. Sound levels between the hydrophone and the surface may have been stronger than those we measured (though complex noise fields arise, particularly in shallow water (see, e.g., Figure 2i-1 in Erbe et al. 2017) [61]. For Endangered SRKW, received levels were above those associated with changes in call amplitude $[62,63]$ and avoidance or changes in behavior [36]. Other Salish Sea marine mammals that have been shown to react with avoidance or startle responses to low-mid frequency sound in this range include harbor porpoise [38,64,65], harbor seals (Phoca vitulina) [66], and gray whales (Eschrichtius robustus) [67]. At lower levels, communication masking has been demonstrated for bottlenose dolphins (Tursiops aduncus) [68], and is likely for other species such as humpback whales (Megaptera novaeangliae) [69]. Although the number of studies that have looked at behavioral responses of fish to noise is small, our received levels overlapped or exceeded thresholds for herring and some other marine fish including sea bass (Dicentrarchus labrax) [39,70]. Studies of how noise may be perceived by and impact seabirds underwater are almost nonexistent. In 2011, an expert panel was convened to establish underwater thresholds for injury to Threatened marbled murrelet from pile driving noise, but injury was defined to include only permanent loss of cochlear hair cells or barotrauma [71]. However, two very recent studies have demonstrated startle, avoidance, and changes in foraging of common murre and Gentoo penguins (Pygoscelis papua) at $105-115 \mathrm{~dB}$ re $1 \mu \mathrm{Pa}$, suggesting that marbled murrelet and other seabirds around Whidbey Island may be impacted by underwater (and in-air) noise from jet aircraft [37,72].

Our results indicate underwater impacts that have been unstudied, underestimated, or otherwise dismissed in the two relevant EIS [17,73] and corresponding Biological Opinion(s) for ESA-listed species $[19,30]$. Of chief concern in this region is SRKW. In the EIS, underwater noise from aircraft were deemed unlikely to adversely affect SRKW (and humpback whales), and to have no effect on critical habitat. The rationale for this conclusion included assertions that whales would have to be at the surface of the water and directly underneath low-altitude aircraft $(<300 \mathrm{~m})$, and that whales were already exposed to boat and ship noise that could "drown out or lessen" any noise from aircraft. Our results indicate instead that noise from Growlers is measurable at least $30 \mathrm{~m}$ under water, with sound levels known to impact whales. Furthermore, these sound levels are comparable to those documented by studies of noise that is experienced by SRKW from small and large vessels [74,75]. The reason that no effects on SRKW critical habitat are assumed is not due to evaluation of noise impacts, but rather to an exemption of waters within the boundaries of military installations from critical habitat designation (see Appendix C, Sections 4.1 and 3.2.5 in [17]). Lastly, the rationale for not considering impacts of aircraft flying higher than $300 \mathrm{~m}$ is based on an agreement with the National Marine Fisheries Service in 2015 to assume that underwater noise from any event where aircraft exceed this altitude will cause no reaction in marine mammals (see Appendix $C$ and Section 4.1 in [17]). This is despite the fact that 
modeled underwater noise for aircraft at altitudes of 300-3000 $\mathrm{m}$ is $128-152 \mathrm{~dB}$ re $1 \mu \mathrm{Pa}$ (see Table 3.0-4 in [73]), exceeding known thresholds for behavioral reactions and adverse impacts on marine mammals, including SRKW (Figure 5). A recent synthesis of underwater noise and vessel disturbance on SRKW by the Washington State Academy of Sciences recommended "defining every interaction with an SRKW as an opportunity to disturb a whale", due to the "fragile condition" of the population [76]. Collectively, we believe that our results create a case for revisiting these impact assessments as well as future inclusion of military aircraft noise in cumulative effects models for SRKW [77].

Evaluating the EIS process against our results further illuminates a problem wherein risk from noise effects is calculated based on the likelihood that individuals (e.g., an individual SRKW or marbled murrelet group) will be exposed to sound levels that result in physical damage (i.e., hearing damage or barotrauma) or direct changes in behavior such as foraging, breeding, or nesting. This does not account for the problem that the habitat itself is being impacted by noise, and becomes less hospitable [78], nor that noise may be added to other stressors $[79,80]$. In this scenario, the very rarity of the species becomes a factor in assuming impacts are discountable, negligible, or insignificant (see Appendix $\mathrm{C}$ and Section 4.1 in [17]). Our purpose in outlining these inconsistencies in environmental impact assessment is not to point fingers at federal oversight agencies or the U.S. military, but to exemplify how knowledge gaps [81], exemptions [5], and use of high noise thresholds for harm intersect to discount or underestimate noise impacts on wildlife, which are increasingly understood to include indirect effects on habitat, abundance and fitness of populations [16,82].

The above challenges are part of an evolving understanding of how to evaluate and mitigate growing noise pollution worldwide. However, our study reveals added challenges specific to noise from MLAF, which is a scarcity of studies resulting in large knowledge gaps with respect to impact. There are substantial logistical and bureaucratic hurdles in monitoring military operations; these have been pointed out in reviews [3,9] as well as experienced by the authors of this study. In particular, the fact that schedules are usually not available in advance and access to operational areas may be restricted increases time and costs of doing these studies. Despite the challenges, there is a strong need to close knowledge gaps, as increased noise from MLAF is predicted to become more common in the future due to base consolidation [2]. Other countries (i.e., Finland and Australia) have recently adopted the Growler platform and may find similar issues in locating training facilities. The problem is not limited to Growler aircraft; the new F-35 is also causing similar concerns and discomfort in areas around airfields $[83,84]$. And while the trend within the U.S. is toward consolidation, the building of new bases and the expansion of military aircraft activity continues worldwide $[41,58,85]$.

In summary, our study suggests the need for underwater noise from Growlers to be included in cumulative effects models [77] and Biological Opinions for ESA-listed species [19,30], as well as more broadly evaluated outside of the immediate vicinity of Whidbey Island. Furthermore, our results show that sound levels and flight operations around NASWI are largely beyond those that have been previously evaluated, supporting calls for a comprehensive health assessment to evaluate consequences for human health and well-being [60]. Finally, we hope that this study stimulates consideration of how to evaluate impacts of intense noise exposure not only for the benefit of this region, but other areas that may face similar challenges now and in the future.

Supplementary Materials: The following are available online at http://www.mdpi.com/2077-1312/8/11/923/s1, Figure S1: LTSAs of in-air recordings, Table S1: Noise metrics and attributes extracted from MLAF studies, Table S2: Summary of FCLP days and time periods, 2015-2019, Data S1: Results of MLAF literature review.

Author Contributions: R.W., E.A. and L.M.K. conceived and designed the study and data collection; R.W., L.T.B., M.S.C. and L.M.K. collected the data; L.M.K. conducted the literature review; C.E., R.W., L.M.K. and M.S.C. analyzed the data; R.W., E.A., L.M.K. and C.E. contributed equipment and analytical tools and software; L.M.K., C.E. and R.W. wrote the paper; all authors contributed to editing and final reviews of the paper. All authors have read and agreed to the published version of the manuscript.

Funding: Multiple small grants and sources of funding made this work possible. The National Parks Conservation Association contributed funds and led a campaign to allow individual donors to contribute to the project. A project 
grant was also awarded from The Suquamish Foundation (Appendix X Award 2018Q226). The funders had no role in study design, data collection and analysis, decision to publish, or preparation of the manuscript.

Acknowledgments: We are grateful for the assistance of several volunteers on this project and manuscript. Heather McCauliffe loaned two Extech sound pressure data loggers. Kimberly Nielsen assisted with the creation of Figure 1, and Toby Hall assisted with deployment and retrieval of the SoundTrap. The manuscript was substantially improved by comments from two anonymous reviewers. Lastly, Rob Williams thanks and acknowledges the Pew Fellows Program in Marine Conservation for support.

Conflicts of Interest: The authors declare no conflict of interest.

\section{References}

1. US Department of the Navy. Record of Decision for the Final Environmental Impact Statement for EA-18G "Growler" Airfield Operations at Naval Air Station Whidbey Island Complex, Island County, WA; United States Department of the Navy: Washington, DC, USA, 2019.

2. Waitz, I.A.; Lukachko, S.P.; Lee, J.J. Military aviation and the environment: Historical trends and comparison to civil aviation. J. Aircr. 2005, 42, 329-339. [CrossRef]

3. Pepper, C.B.; Nascarella, M.A.; Kendall, R.J. A review of the effects of aircraft noise on wildlife and humans, current control mechanisms, and the need for further study. Environ. Manag. 2003, 32, 418-432. [CrossRef]

4. Basner, M.; Clark, C.; Hansell, A.; Hileman, J.I.; Janssen, S.; Shepherd, K.; Sparrow, V. Aviation noise impacts: State of the science. Noise Health 2017, 19, 41-50.

5. Truban, E. Military exemptions from environmental regulations: Unwarranted special treatment or necessary relief. Villanova Environ. Law J. 2004, 15, 139-171.

6. Okinawa Prefectural Government. A Report on the Aircraft Noise as a Public Health Problem in Okinawa; Department of Culture and Environmental Affairs: Okinawa, Japan, 1999.

7. Kerry, G.; Weeler, P.D.; Hempstock, T.I.; James, D.J. Impulse noise metrics and their application to noise from low flying military jet aircraft. J. Acoust. Soc. Am. 1998, 103, 2800. [CrossRef]

8. Shannon, G.; McKenna, M.F.; Angeloni, L.M.; Crooks, K.R.; Fristrup, K.M.; Brown, E.; Warner, K.A.; Nelson, M.D.; White, C.; Briggs, J.; et al. A synthesis of two decades of research documenting the effects of noise on wildlife: Effects of anthropogenic noise on wildlife. Biol. Rev. 2016, 91, 982-1005. [CrossRef] [PubMed]

9. Efroymson, R.A.; Suter, G.W., II. Ecological risk assessment framework for low-altitude aircraft overflights: II. Estimating effects on wildlife. Risk Anal. 2001, 21, 263-274. [CrossRef] [PubMed]

10. Kuehne, L.; Olden, J. Military flights threaten the wilderness soundscapes of the Olympic Peninsula, Washington. Northwest Sci. 2020, 94, 188-202.

11. Erbe, C.; Williams, R.; Parsons, M.; Parsons, S.K.; Hendrawan, I.G.; Dewantama, I.M.I. Underwater noise from airplanes: An overlooked source of ocean noise. Mar. Pollut. Bull. 2018, 137, 656-661. [CrossRef]

12. Williams, R.; Erbe, C.; Dewantama, I.M.I.; Hendrawan, I.G. Effect on ocean noise: Nyepi, a Balinese day of silence. Oceanography 2018, 31, 16-18. [CrossRef]

13. Eller, A.I.; Cavanagh, R.C. Subsonic Aircraft Noise at and Beneath the Ocean Surface: Estimation of Risk for Effects on Marine Mammals; Science Applications International Corporation: McLean, VA, USA, 2000.

14. Ashe, E.; Noren, D.P.; Williams, R. Animal behaviour and marine protected areas: Incorporating behavioural data into the selection of marine protected areas for an endangered killer whale population. Anim. Conserv. 2010, 13, 196-203. [CrossRef]

15. Kunc, H.P.; Schmidt, R. The effects of anthropogenic noise on animals: A meta-analysis. Biol. Lett. 2019, 15, 20190649. [CrossRef] [PubMed]

16. Francis, C.D.; Barber, J.R. A framework for understanding noise impacts on wildlife: An urgent conservation priority. Front. Ecol. Environ. 2013, 11, 305-313. [CrossRef]

17. US Department of the Navy. Final Environmental Impact Statement for EA-18G Growler Airfield Operations at Naval Air Station Whidbey Island Complex; United States Department of the Navy: Washington, DC, USA, 2018.

18. US Department of the Navy. Flight Operations Notification for NAS Whidbey Island Complex. Available online: https://www.cnic.navy.mil/regions/cnrnw/installations/nas_whidbey_island/news/news_ releases/field-carrier-landing-practice-at-nas-whidbey-island-complex-for.html (accessed on 20 June 2020).

19. US Fish and Wildlife Service. Biological Opinion: Naval Air Station Whidbey Island Complex EA-18G "Growler" Airfield Operations Project; United States Fish and Wildlife Service: Washington, DC, USA, 2018. 
20. International Organization for Standardization. International ISO Standard 18405, Underwater Acoustics-Terminology, 1st ed.; International Organization for Standardization: Geneva, Switzerland, 2017.

21. Branstetter, B.K.; Leger, J.S.; Acton, D.; Stewart, J.; Houser, D.; Finneran, J.J.; Jenkins, K. Killer whale (Orcinus orca) behavioral audiograms. J. Acoust. Soc. Am. 2017, 141, 2387-2398. [CrossRef]

22. Erbe, C.; Reichmuth, C.; Cunningham, K.; Lucke, K.; Dooling, R. Communication masking in marine mammals: A review and research strategy. Mar. Pollut. Bull. 2016, 103, 15-38. [CrossRef] [PubMed]

23. Johansen, S.; Larsen, O.N.; Christensen-Dalsgaard, J.; Seidelin, L.; Huulvej, T.; Jensen, K.; Lunneryd, S.-G.; Boström, M.; Wahlberg, M. In-air and underwater hearing in the great cormorant (Phalacrocorax carbo sinensis). In Effects of Noise on Aquatic Life II; Springer: Berlin/Heidelberg, Germany, 2016; pp. 505-512.

24. Crowell, S.E.; Wells-Berlin, A.M.; Therrien, R.E.; Yannuzzi, S.E.; Carr, C.E. In-air hearing of a diving duck: A comparison of psychoacoustic and auditory brainstem response thresholds. J. Acoust. Soc. Am. 2016, 139, 3001-3008. [CrossRef]

25. Mooney, T.A.; Smith, A.; Larsen, O.N.; Hansen, K.A.; Wahlberg, M.; Rasmussen, M.H. Field-based hearing measurements of two seabird species. J. Exp. Biol. 2019, 222. [CrossRef]

26. Okanoya, K.; Dooling, R.J. Hearing in passerine and psittacine birds: A comparative study of absolute and masked auditory thresholds. J. Comp. Psychol. 1987, 101, 7. [CrossRef]

27. McKenna, M.F.; Shannon, G.; Fristrup, K. Characterizing anthropogenic noise to improve understanding and management of impacts to wildlife. Endanger Species Res. 2016, 31, 279-291. [CrossRef]

28. Haralabidis, A.S.; Dimakopoulou, K.; Vigna-Taglianti, F.; Giampaolo, M.; Borgini, A.; Dudley, M.-L.; Pershagen, G.; Bluhm, G.; Houthuijs, D.; Babisch, W. Acute effects of night-time noise exposure on blood pressure in populations living near airports. Eur. Heart J. 2008, 29, 658-664. [CrossRef]

29. Basner, M.; Buess, H.; Mueller, U.; Plath, G.; Samel, A. Aircraft noise effects on sleep: Final results of DLR laboratory and field studies of 2240 polysomnographically recorded subject nights. In Proceedings of the 33rd International Congress and Exposition on Noise Control Engineering, Prague, Czech Republic, 22-25 August 2004; pp. 22-25.

30. US Fish and Wildlife Service. Biological Opinion: Navy's Northwest Training and Testing Activities; United States Fish and Wildlife Service: Washington, DC, USA, 2016.

31. Hayward, L.S.; Bowles, A.E.; Ha, J.C.; Wasser, S.K. Impacts of acute and long-term vehicle exposure on physiology and reproductive success of the northern spotted owl. Ecosphere 2011, 2, 1-20. [CrossRef]

32. Delaney, D.K.; Grubb, T.G.; Beier, P.; Pater, L.L.; Reiser, M.H. Effects of helicopter noise on Mexican spotted owls. J. Wildl. Manag. 1999, 63, 60-76. [CrossRef]

33. Mason, J.T.; McClure, C.J.; Barber, J.R. Anthropogenic noise impairs owl hunting behavior. Biol. Conserv. 2016, 199, 29-32. [CrossRef]

34. Goudie, R.I.; Jones, I.L. Dose-response relationships of harlequin duck behaviour to noise from low-level military jet over-flights in central Labrador. Biol. Conserv. 2004, 31, 289-298. [CrossRef]

35. Maier, J.A.; Murphy, S.M.; White, R.G.; Smith, M.D. Responses of caribou to overflights by low-altitude jet aircraft. J. Wildl. Manag. 1998, 62, 752-766. [CrossRef]

36. Williams, R.; Bain, D.E.; Ford, J.K.; Trites, A.W. Behavioural responses of male killer whales to a 'leapfrogging' vessel. J. Cetacean Res. Manag. 2002, 4, 305-310.

37. Hansen, K.A.; Hernandez, A.; Mooney, T.A.; Rasmussen, M.H.; Sørensen, K.; Wahlberg, M. The common murre (Uria aalge), an auk seabird, reacts to underwater sound. J. Acoust. Soc. Am. 2020, 147, 4069-4074. [CrossRef]

38. Kastelein, R.A.; Steen, N.; Gransier, R.; Wensveen, P.J.; de Jong, C.A.F. Threshold received sound pressure levels of single 1-2 kHz and 6-7 kHz up-sweeps and down-sweeps causing startle responses in a harbor porpoise (Phocoena phocoena). J. Acoust. Soc. Am. 2012, 131, 2325-2333. [CrossRef] [PubMed]

39. Doksæter, L.; Handegard, N.O.; Godø, O.R.; Kvadsheim, P.H.; Nordlund, N. Behavior of captive herring exposed to naval sonar transmissions $(1.0-1.6 \mathrm{kHz})$ throughout a yearly cycle. J. Acoust. Soc. Am. 2012, 131, 1632-1642. [CrossRef]

40. Houser, D.S.; Martin, S.W.; Finneran, J.J. Behavioral responses of California sea lions to mid-frequency (3250-3450 Hz) sonar signals. Mar. Environ. Res. 2013, 92, 268-278. [CrossRef] 
41. Gelderblom, F.B.; Gjestland, T.T.; Granoien, I.L.; Taraldsen, G. The impact of civil versus military aircraft noise on noise annoyance. In INTER-NOISE and NOISE-CON Congress and Conference Proceedings; Institute of Noise Control Engineering: Reston, VA, USA, 2014; Volume 249, pp. 786-795.

42. Wu, Y.-X.; Liu, X.L.; Wang, B.-G.; Wang, X.Y. Aircraft noise-induced temporary threshold shift. Aviat. Space Environ. Med. 1989, 60, 268-270. [PubMed]

43. Yong, J.S.; Wang, D.-Y. Impact of noise on hearing in the military. Mil. Med. Res. 2015, 2, 1-6. [CrossRef] [PubMed]

44. Goudie, R.I. Multivariate behavioural response of harlequin ducks to aircraft disturbance in Labrador. Environ. Conserv. 2006, 33, 28-35. [CrossRef]

45. Lilly, J. Whidbey Island Military Jet Noise Measurements; JGL Acoustics, Inc.: Issaquah, WA, USA, 2013.

46. Lilly, J. Whidbey Island Military Jet Noise Measurements; JGL Acoustics, Inc.: Issaquah, WA, USA, 2016.

47. Lilly, J. Military Jet Noise Measurements OLF Coupeville Whidbey Island, WA; JGL Acoustics, Inc.: Issaquah, WA, USA, 2020.

48. Pipkin, A. Ebey's Landing National Historical Reserve Acoustical Monitoring Report; National Park Service: Fort Collins, CO, USA, 2016.

49. Hiramatsu, K.; Matsui, T.; Ito, A.; Miyakita, T.; Osada, Y.; Yamamoto, T. The Okinawa study: An estimation of noise-induced hearing loss on the basis of the records of aircraft noise exposure around Kadena Air Base. J. Sound Vib. 2004, 277, 617-625. [CrossRef]

50. Miyakita, T.; Yoza, T.; Matsui, T.; Ito, A.; Hiramatsu, K.; Osada, Y.; Yamamoto, T. An epidemiological study regarding the hearing acuity of residents in the area with high level of aircraft noise. Jpn. J. Hyg. 2001, 56, 577-587. [CrossRef] [PubMed]

51. Kuronen, P.; Pääkkönen, R.; Savolainen, S. Low-altitude overflights of fighters and the risk of hearing loss. Aviat. Space Environ. Med. 1999, 70, 650-655.

52. Ising, H.; Joachims, Z.; Babisch, W.; Rebentisch, E. Effects of military low-altitude flight noise Part I: Temporary threshold shift in humans. Z. Fur Audiol. 1999, 38, 118-127.

53. Matsui, T.; Uehara, T.; Miyakita, T.; Hiramatsu, K.; Yamamoto, T. Dose-response relationship between hypertension and aircraft noise exposure around Kadena airfield in Okinawa. In Proceedings of the 9th International Congress on Noise as a Public Health Problem, Foxwoods, CT, USA, 21-25 July 2008.

54. Miyazaki, M. Circulatory effect of jet noise, with special reference to cerebral circulation. Jpn. Circ. J. 1978, 42, 1019-1024. [CrossRef]

55. Ising, H.; Michalak, R. Effects of noise from military low-level flights on humans (part II. Noise as a Public Health Problem). New Adv. Noise Res. 1990, 1, 21-25.

56. Ising, H.; Rebentisch, E.; Poustka, F.; Curio, I. Annoyance and health risk caused by military low-altitude flight noise. Int. Arch. Occup. Environ. Health 1990, 62, 357-363. [CrossRef]

57. Lukas, J.S.; Dobbs, M.E.; Kryter, K.D. Disturbance of Human Sleep by Subsonic Jet Aircraft Noise and Simulated Sonic Booms; National Aeronautics and Space Administration: Washington, DC, USA, 1971.

58. Tokuda, Y.; Barnett, P.B. Constructing a new US Military Base: A health threat to Okinawan people. Environ. Justice 2017, 10, 23-25. [CrossRef]

59. Basner, M.; Babisch, W.; Davis, A.; Brink, M.; Clark, C.; Janssen, S.; Stansfeld, S. Auditory and non-auditory effects of noise on health. Lancet 2014, 383, 1325-1332. [CrossRef]

60. Washington State Department of Health. Comments on the Environmental Impact Statement for EA-18G Growler Airfield Operations at Naval Air Station Whidbey Island; Washington State Department of Health: Tumwater, VA, USA, 2017.

61. Erbe, C.; Parsons, M.; Duncan, A.; Osterrieder, S.K.; Allen, K. Aerial and underwater sound of unmanned aerial vehicles (UAV). J. Unmanned Veh. Syst. 2017, 5, 92-101. [CrossRef]

62. Holt, M.M.; Noren, D.P.; Emmons, C.K. Effects of noise levels and call types on the source levels of killer whale calls. J. Acoust. Soc. Am. 2011, 130, 3100-3106. [CrossRef] [PubMed]

63. Holt, M.M.; Noren, D.P.; Veirs, V.; Emmons, C.K.; Veirs, S. Speaking up: Killer whales (Orcinus orca) increase their call amplitude in response to vessel noise. J. Acoust. Soc. Am. 2009, 125, EL27-EL32. [CrossRef] [PubMed]

64. Kastelein, R. Brief behavioral response threshold levels of a harbor porpoise (Phocoena phocoena) to five helicopter dipping sonar signals (1.33 to $1.43 \mathrm{kHz}$ ). Aquat. Mamm. 2013, 39, 162-173. [CrossRef] 
65. Kastelein, R.A.; van Heerden, D.; Gransier, R.; Hoek, L. Behavioral responses of a harbor porpoise (Phocoena phocoena) to playbacks of broadband pile driving sounds. Mar. Environ. Res. 2013, 92, 206-214. [CrossRef]

66. Kastelein, R.A.; van der Heul, S.; Verboom, W.C.; Triesscheijn, R.J.; Jennings, N.V. The influence of underwater data transmission sounds on the displacement behaviour of captive harbour seals (Phoca vitulina). Mar. Environ. Res. 2006, 61, 19-39. [CrossRef]

67. Malme, C.I.; Miles, P.R.; Clark, C.W.; Tyack, P.; Bird, J.E. Investigations of the Potential Effects of Underwater Noise from Petroleum Industry Activities on Migrating Gray Whale Behavior; Bolt Beranek and Newman Inc.: Cambridge, MA, USA, 1983.

68. Lemon, M.; Lynch, T.P.; Cato, D.H.; Harcourt, R.G. Response of travelling bottlenose dolphins (Tursiops aduncus) to experimental approaches by a powerboat in Jervis Bay, New South Wales, Australia. Biol. Conserv. 2006, 127, 363-372. [CrossRef]

69. Risch, D.; Corkeron, P.J.; Ellison, W.T.; Van Parijs, S.M. Changes in humpback whale song occurrence in response to an acoustic source $200 \mathrm{~km}$ away. PLoS ONE 2012, 7, e29741. [CrossRef]

70. Kastelein, R.A.; Van Der Heul, S.; Verboom, W.C.; Jennings, N.; Van Der Veen, J.; de Haan, D. Startle response of captive North Sea fish species to underwater tones between 0.1 and $64 \mathrm{kHz}$. Mar. Environ. Res. 2008, 65, 369-377. [CrossRef] [PubMed]

71. Science Applications International Corporation. Environmental Science Panel for Marbled Murrelet Underwater Noise Injury Threshold; Science Applications International Corporation: Bothell, WA, USA, 2011.

72. Sørensen, K.; Neumann, C.; Dähne, M.; Hansen, K.A.; Wahlberg, M. Gentoo penguins (Pygoscelis papua) react to underwater sounds. R. Soc. Open Sci. 2020, 7, 191988. [CrossRef] [PubMed]

73. US Department of the Navy. Northwest Training and Testing Final Supplemental Environmental Impact Statement/Overseas Environmental Impact Statement (FEIS/OEIS); United States Department of the Navy: Washington, DC, USA, 2020.

74. Houghton, J.; Holt, M.M.; Giles, D.A.; Hanson, M.B.; Emmons, C.K.; Hogan, J.T.; Branch, T.A.; VanBlaricom, G.R. The relationship between vessel traffic and noise levels received by killer whales (Orcinus orca). PLoS ONE 2015, 10, e0140119. [CrossRef] [PubMed]

75. Veirs, S.; Veirs, V.; Wood, J.D. Ship noise extends to frequencies used for echolocation by endangered killer whales. PeerJ 2016, 4, e1657. [CrossRef] [PubMed]

76. Washington State Academy of Sciences. Summary of Key Research Findings about Underwater Noise and Vessel Disturbance; Washington State Academy of Sciences: Seattle, WA, USA, 2020.

77. Lacy, R.C.; Williams, R.; Ashe, E.; Balcomb, K.C., III; Brent, L.J.; Clark, C.W.; Croft, D.P.; Giles, D.A.; MacDuffee, M.; Paquet, P.C. Evaluating anthropogenic threats to endangered killer whales to inform effective recovery plans. Sci. Rep. 2017, 7, 1-12. [CrossRef] [PubMed]

78. Williams, R.; Clark, C.W.; Ponirakis, D.; Ashe, E. Acoustic quality of critical habitats for three threatened whale populations. Anim. Conserv. 2014, 17, 174-185. [CrossRef]

79. Maxwell, S.M.; Hazen, E.L.; Bograd, S.J.; Halpern, B.S.; Breed, G.A.; Nickel, B.; Teutschel, N.M.; Crowder, L.B.; Benson, S.; Dutton, P.H. Cumulative human impacts on marine predators. Nat. Commun. 2013, 4, 1-9. [CrossRef]

80. Williams, R.; Thomas, L.; Ashe, E.; Clark, C.W.; Hammond, P.S. Gauging allowable harm limits to cumulative, sub-lethal effects of human activities on wildlife: A case-study approach using two whale populations. Mar. Policy 2016, 70, 58-64. [CrossRef]

81. Southall, B.L.; Finneran, J.J.; Reichmuth, C.; Nachtigall, P.E.; Ketten, D.R.; Bowles, A.E.; Ellison, W.T.; Nowacek, D.P.; Tyack, P.L. Marine mammal noise exposure criteria: Updated scientific recommendations for residual hearing effects. Aquat. Mamm. 2019, 45, 125-232. [CrossRef]

82. Williams, R.; Wright, A.J.; Ashe, E.; Blight, L.K.; Bruintjes, R.; Canessa, R.; Clark, C.W.; Cullis-Suzuki, S.; Dakin, D.T.; Erbe, C. Impacts of anthropogenic noise on marine life: Publication patterns, new discoveries, and future directions in research and management. Ocean Coast. Manag. 2015, 115, 17-24. [CrossRef]

83. Mizokami, K. The F-35 Could Make Some Neighborhoods in the U.S. Unliveable. Available online: https: //www.popularmechanics.com/military/aviation/a28625774/f-35-too-loud/ (accessed on 20 September 2020). 
84. Verburg, S. Residents Weary of Jet Noise Worry about F-35. Available online: https: //madison.com/wsj/news/local/environment/residents-weary-of-jet-noise-worry-about-f-35/article_ d1a3c79a-34bb-5f65-8093-5c3c98cecae3.html (accessed on 20 September 2020).

85. Cabestan, J.-P. China's military base in Djibouti: A microcosm of China's growing competition with the United States and new bipolarity. J. Contemp. China 2020, 29, 731-747. [CrossRef]

Publisher's Note: MDPI stays neutral with regard to jurisdictional claims in published maps and institutional affiliations.

(C) 2020 by the authors. Licensee MDPI, Basel, Switzerland. This article is an open access article distributed under the terms and conditions of the Creative Commons Attribution (CC BY) license (http://creativecommons.org/licenses/by/4.0/). 